\title{
ENTRE FRANCISCANOS E BENEDITINOS: o caso de Domingos do Loreto Couto (1696-1762)
}

\author{
Bruno Kawai Souto Maior de Melo*
}

\begin{abstract}
RESUMO: O presente artigo busca analisar a trajetória de vida do religioso pernambucano Domingos do Loreto Couto, reconhecido pela historiografia como autor de importante obra para o entendimento da primeira metade do século XVIII: Desagravos do Brasil e Glórias de Pernambuco. Não priorizaremos o interesse de nossa personagem à sua atividade de cronista, antes, utilizaremos a sua trajetória como elemento que nos permitirá ter uma visão mais alargada do período investigado, principalmente no que toca aos casos de religiosos que transitaram entre as Ordens Regulares, prática recorrente até o segundo quartel do século XVIII. Assim sendo, acreditamos que a trajetória de Loreto Couto nos convida a compreender, em escala micro, as estruturas de poder da esfera eclesiástica, os diálogos e embates entre os clérigos regulares e os poderes diocesanos, ou mesmo a relação entre as dioceses ultramarinas e o centro da monarquia cristã.

PALAVRAS-CHAVE: Igreja; Domingos do Loreto Couto; Transitados.
\end{abstract}

\section{Between Franciscan and Benedictine: the case of Domingos do Loreto Couto (1696-1762)}

ABSTRACT: The present paper analyses the life of Domingos do Loreto Couto as a religious man recognized by historiography as the author of an important book to understand the early 18th century: Desagravos do Brasil e Glorias de Pernambuco. We are not interested in our author as a writer of chronicles; we will use his academic path as an element to get an overview of the selected period, especially regarding the cases of regulars who moved between Orders, a usual practice until the second quarter of the 18th century. Thus, we believe that Loreto Couto's path invites us to understand, on a small scale, the power structure of the ecclesiastical sphere, the dialogue and disagreements between the regular clerics and the diocesan powers, or even the relations between the overseas dioceses and the center of the Christian monarchy.

KEYWORDS: Catholic Church; Domingos do Loreto Couto; regulars moving between Orders.

\section{Entre Franciscanos y Benedictinos: el caso de Domingos do Loreto Couto (1696 - 1762)}

RESUMEN: Este artículo analiza la trayectoria de vida del religioso pernambucano, Domingos do Couto Loreto, reconocido en la historia como el autor de una importante obra para el entendimiento de la primera mitad del siglo XVIII: Desagravos do Brasil e Glórias de Pernambuco. No es nuestro objetivo dar énfasis al perfil de cronista de nuestro personaje, sino que observaremos su trayectoria como elemento que nos permitirá alcanzar una visión más amplia del periodo en destaque, principalmente en lo que se refiere a casos de algunos religiosos que transitaban entre las Órdenes Regulares, práctica existente hasta el fin del siglo XVIII. Por lo tanto, creemos que la trayectoria de Loreto nos invita a comprender sencilla y específicamente las estructuras de poder en el ámbito eclesiástico, los diálogos y enfrentamientos entre los clérigos regulares y los poderes diocesanos, o hasta mismo la relación de conectividad entre las diócesis ultramarinas y el centro de la monarquía cristiana. PALABRAS-CLAVE: Iglesia; Domingos do Loreto Couto; Transitados.

\footnotetext{
*Mestre em História pela Universidade Federal de Pernambuco. Professor dos Cursos de Pós-Graduação da Faculdade Escritor Osman da Costa Lins. E-mail: bruno.kawai@yahoo.com.br.
} 


\section{A Genealogia}

Corria os anos iniciais da década de vinte do século XVIII. Na capitania de Pernambuco, um conjunto de coristas da ordem de São Francisco do convento de Santo Antônio do Recife aguardava a profissão dos primeiros votos entre os frades menores, impossibilitada devido a vacância dos bispados de Olinda, Rio de Janeiro e o arcebispado da Bahia. ${ }^{1}$ Por haver necessidade imediata de novos irmãos na província, como nos diz o Procurador Geral da Ordem ${ }^{2}$, foram enviados a Lisboa, onde deveriam professar e retornar em seguida.

Dentre os coristas que foram ao centro da monarquia portuguesa, encontrava-se Domingos do Loreto Couto. Nascido em Recife, provavelmente no ano de $1696^{3}$, era filho de Laura Soares Godim e João Álvares do Couto. Sua mãe, natural da terra, era filha do Capitão Mor Marcos Velho Gondim, fidalgo da casa Real, cavaleiro professo na Ordem de Cristo, capitão de infantaria paga na cidade do Maranhão e capitão mor do Pará, e de Isabel Soares da Fonseca, filha do Capitão Bartholomeu Soares Canha. ${ }^{4}$ Quanto ao seu pai, temos escassos dados biográficos. Originário do Couto do Capareiros, João Álvares do Couto ingressou na Misericórdia de Olinda com entrada no ano de 1689. Também foi membro da Ordem Terceira da Penitência do Recife, com inscrição no livro de Termos de Entrada registrada em 14 de agosto de $1695 .^{5}$

A relação da família de Domingos do Loreto Couto com a ordem franciscana deu-se de forma estreita, além de seu pai, membro da Ordem Terceira, sua mãe foi enterrada na capela da mesma Ordem, em Recife. ${ }^{6}$ Uma de suas irmãs, Ana da Fonseca Gondim, casada com o coronel Manoel Araújo de Carvalho, proprietário de avultosa fazenda de gado Vacum na Paraíba, que passaria a ser tutelada por Loreto Couto futuramente, "fazia da Igreja de Santo Antonio do Recife sua habitação, ouvindo missa todos os dias em que eram ditas". ${ }^{7}$ Outro irmão de Loreto Couto, também padre, chamado José Álvares Couto, foi irmão professo na Ordem Terceira de São Francisco com entrada em 08 de dezembro de $1709 .{ }^{8}$

O ramo Couto da família de Domingos do Loreto Couto origina-se do Minho, de uma região chamada de Capareiros ou Couto dos Capereiros, ao norte de Portugal, pertencente à diocese de Braga desde 1126. ${ }^{9}$ Segundo Domingos do Loreto Couto, seu pai era neto de Álvaro Eane de Coutto, descendente de Ruy Gonçalves de Coutto, cavaleiro parmesão. ${ }^{10}$ Muito provavelmente João Álvares de Couto veio a Pernambuco a convite de seu irmão Manuel Álvares do Couto, que residia em Olinda desde 1685. Sabe-se através do processo de 
Habilitação ao Santo Ofício de Domingos Rodrigues Bandeira, que em 1700, Manuel Álvares do Couto vivia dos seus negócios e residia próximo aos quatro cantos em Olinda. ${ }^{11}$

A vinda de João Álvares Couto à Pernambuco reflete uma prática rotineira de migração, potencializada nas décadas posteriores a expulsão dos flamengos, quando Recife passa a ter peso fulcral na dinâmica econômica da capitania de Pernambuco e sedia importantes casas comerciais fundadas por negociantes portugueses, na quase totalidade cristãos-velhos oriundos do norte de Portugal. ${ }^{12}$ Convidado pelo irmão, viria a Pernambuco talvez com a promessa de "fazer a América", sendo apadrinhado por esse em seu processo de fixação no novo mundo. ${ }^{13}$ Ao se ambientar a terra, trataria de se inserir nos espaços de poder que lhe permitisse um lugar de adjetivação frente aos poderes locais, já que em monarquias de caráter corporativista como a Portuguesa, adjetivar, seria, tanto ou mais do que descrever, classificar socialmente. ${ }^{14}$

Seus primeiros passos foram trilhados de forma estratégica, já que participava de dois dos importantes espaços de atuação política das elites de Recife e Olinda. O ingresso na Misericórdia de Olinda lhe possibilitou figurar entre importante elite da terra, na medida em que o acesso a essa instituição era restrito a um seleto grupo de condição e qualidade especificas. ${ }^{15}$ No caso da Misericórdia de Olinda, um conjunto de restrições impossibilitava a inserção dos comerciantes recifenses na instituição, principalmente o defeito mecânico e os costados (nomeadamente ascendência cristã nova), o que fazia da Misericórdia um importante lócus de reafirmação da "nobreza da terra" em detrimento dos negociantes recifenses. ${ }^{16}$

Do lado recifense foi irmão professo da Ordem Terceira de São Francisco, importante espaço de atuação e representatividade dos comerciantes de Recife. Segundo Evaldo Cabral de Mello, antes da criação da Misericórdia de Recife (1737) e mesmo depois, a Ordem Terceira de São Francisco funcionou como a contrapartida mascatal da Santa Casa Olindense, seja no plano simbólico do prestígio, seja no prático, dos serviços dispensados aos sócios. ${ }^{17} \mathrm{~A}$ mobilidade nestas duas instituições nos permite refletir sobre o prestígio adquirido por João Álvares Couto nos anos posteriores a sua chegada a capitania. Pouco tempo depois já era descrito por Frei Jaboatão como um dos importantes e antigos moradores da povoação do Recife. $^{18}$

Seu casamento com uma mulher que vinculava-se a uma importante família da terra, os Gondim, descendentes da famosa família Gondini de França ${ }^{19}$, contribuiu com sua inserção nos círculos de poder da capitania, já que, estabelecido nas instituições de maior representatividade do período, faltava-lhe um vínculo mais profundo que lhe possibilitasse a 
criação de raízes, o que seguindo o perfil dos negociantes portugueses que migravam para o Recife nesse período, significaria uma lucrativa aliança matrimonial. Se unir a uma família, que por sua inserção social possuísse um poder político efetivo, garantiria a sua integração nos equilíbrios sociais existentes. ${ }^{20}$

O consórcio conjugal entre João Álvares Couto e Laura Soares Gondim teve como produto cinco filhos, três mulheres e dois homens. As mulheres casaram com representantes de importantes famílias das capitanias da Paraíba e Pernambuco, enquanto os dois homens seguiram a carreira eclesiástica, nesse período entendida como possibilidade de mobilidade social, e pretendida tanto pelos filhos da nobreza titular do reino quanto pelas famílias das demais camadas sociais. ${ }^{21}$

Nascido em 1696, muito provavelmente Domingos do Loreto Couto tornou-se noviço depois do ano de 1712, já que de acordo com o estatuto da Província de Santo Antônio do Brasil esses só poderiam ser aceitos a partir dos dezesseis anos de idade. De acordo com o mesmo estatuto, as casas conventuais que aceitavam a noviços eram apenas duas: Paraguaçu, na capitania da Bahia, onde deveriam ser iniciados os pernambucanos; e Igarassu, em Pernambuco, onde os noviços baianos iniciavam seus estudos. ${ }^{22}$ Sobre a fase que vai do seu nascimento até sua entrada na ordem, sua possível estadia no convento de Paraguaçu etc., pouco sabemos, nos restando inferências retiradas de seu processo, futuramente analisado.

\section{Entre Lisboa e o Norte da América Portuguesa}

A história que pretendemos contar inicia-se com a ida de Domingos do Loreto Couto para Lisboa, o que teria ocorrido entre os idos de 1724 e 1725. Como já dito, seu deslocamento ao centro da Pluricontinental Monarquia Portuguesa teria como objetivo sua profissão na Ordem dos Irmãos Menores. Profissão realizada, deveria retornar a Pernambuco juntamente com os demais coristas que o acompanharam. Entretanto, diferentemente de seus pares, permaneceu em Lisboa durante oito anos, período em que realizou alguns atos considerados pelo Procurador Geral da Ordem dos Franciscanos de "extravagantes", dentre eles: o furto de uma cama do convento das freiras da Esperança, a venda de conhecimentos falsos de uns fechos de açúcar e a prática de pedir dinheiro emprestado. ${ }^{23}$

Sobre o período em que Domingos do Loreto Couto permaneceu em Portugal, pouco sabemos, além das poucas linhas escritas no definitório realizado no convento de Santo Antônio da Bahia em cinco de janeiro de $1735 .{ }^{24}$ Esse não deixa claro quais teriam sido os 
atos de "extravagâncias" realizados pelo franciscano, muito menos esclarece o pitoresco episódio do furto da cama do convento das freiras da Esperança, apresentado sem grande relevância pelos definidores.

Alcunhado de extravagante, passou a ser perseguido pelos Procuradores da Ordem em Lisboa, até que foi aprisionado e enviado para Bahia, onde deveria ser recolhido ao convento de Salvador, casa capitular da Província de Santo Antônio. Ao chegar ao porto de Salvador, um dos mais movimentados da América Portuguesa, localizado na cidade baixa, onde encontrava-se a zona comercial com armazéns e trapiches, bem como considerável fluxo e refluxo de mercadorias vindas e idas de aquém e além $\operatorname{mar}^{25}$, Domingos do Loreto Couto encontrou ambiente favorável pra empreender uma fuga, que, talvez pelo planejamento prévio, ou mesmo pelo contexto favorecedor, logrou êxito. Na capital da América Portuguesa, passou mais dois anos e meio fora das regras de sua ordem: em apostasia ${ }^{26}$, computando um pouco mais de uma década em que professara e que não havia retornado a sua casa conventual.

Nada sabemos sobre os dois anos e meio que passou na Bahia fora do convento, quais suas práticas, vivências etc. Segundo o definitório já citado, teria sido aprisionado em refúgio na casa do falecido Capitão Francisco Vieira de Farias, sob mandado do conde de Sabugosa, então vice rei do Estado do Brasil. Entregue aos seus prelados, foi acusado de durante o período em que viveu fora do convento ter sido visto em trajes seculares e pedindo esmola a diversas pessoas na cidade de Salvador. Considerado culpado, foi condenado a seis meses de cárcere formal, durante os quais lhe dariam "três disciplinas por mão alheia no refeitório a cada semana, a saber nas segundas, quartas e sextas", assim como "teria depois lugar abaixo dos religiosos deste estado". ${ }^{27}$

Condenado a passar os próximos seis meses de sua vida sob a disciplina que lhe foi imposta, Loreto Couto nem se quer foi recolhido ao cárcere, alegando febre intensa foi enviado à enfermaria do convento para se curar. Curado da febre, queixou-se de dores em uma das pernas e de achaques incontroláveis, o que livrou-lhe mais uma vez do cárcere e das disciplinas. Depois de examinado pelos médicos do convento, atestou-se que sua melhora dependeria de banhos constantes em rio corrente, o que se faria impossível no convento. Diante da situação, foi lhe dada licença para retornar a Pernambuco, onde se estalaria na fazenda de um cunhado, e assim trataria de seus achaques.

Na realidade, Domingos do Loreto Couto recebeu uma licença de Hábito Retento, que consiste em um recurso para viver fora do claustro. Neste sentido, o regular que solicita este 
privilégio ficaria sob a proteção do Provincial, do Abade, do Ordinário/bispo ou do Papa. No caso em tela, foi o Provincial da Província de Santo António do Brasil que lhe permitiu a retenção de suas funções no convento pelo período de sete $\operatorname{anos}^{28}$, momento esse em que se dedicaria a cuidar de suas enfermidades na fazenda de seu cunhado.

De acordo com o Procurador Geral dos Franciscanos, as enfermidades reclamadas por Domingos do Loreto Couto eram falsas, e utilizadas por ele como estratégia para prosseguir fora do convento. Fr. Inácio das Neves foi talvez o maior perseguidor de Loreto Couto, além de ferrenho defensor de reformas morais na ordem na primeira metade do século XVIII.

De forma estratégica ou não, a licença de Hábito de Retento de Loreto Couto lhe foi dada como previsto no estatuto da Província Franciscana do Brasil, o que tornava seu retorno aos "ares pátrios" legítimo. Teria voltado a Pernambuco ainda em 1735, como se lê em carta do Abade de São Bento do Brasil, mesmo ano em que o definitório franciscano teria sido realizado contra ele. ${ }^{29}$ Segundo José Antônio Gonsalves de Mello, sabe-se que em 1738 Domingos do Loreto Couto já estaria com certeza na antiga capitania duartina, devido a uma doação que teria feito em nome de sua irmã, Ana da Fonseca Gondim. Sua irmã teria ofertado um rosário de contas de ouro para o ornamento da imagem de Nossa Senhora do Rosário, na Igreja da mesma invocação localizada em Santo Antônio, na vila do Recife. ${ }^{30}$

Ao retornar a Pernambuco, Domingos do Loreto Couto passa a tutelar suas irmãs que há pouco haviam enviuvado, eram elas: Ana da Fonseca Gondim, casada com o capitão Manuel de Araújo Carvalho; e Maria de Araújo Velha, mulher de João da Costa de Araújo. Como seu outro irmão, o padre João Álvares do Couto, já havia falecido ${ }^{31}$, e seu pai já se encontrava octogenário, coube a Loreto Couto administrar os negócios da família, bem como cuidar da educação de seus sobrinhos órfãos. Em um abaixo-assinado, realizado por parentes de Domingos do Loreto Couto, comenta-se que foi por sua ação que as posses de suas irmãs, “copiosa fazendas no sertão da Paraíba", continuaram como patrimônio da família, na qual ele passaria a gerenciar. Usa-se o exemplo da fazenda do Brejo, sertão da Paraíba, destinada à criação de gado vacum e cavalar, em que o coronel Francisco Dias de Ávila, senhorio da casa da Torre, pretendia desapossar "com violência" suas irmãs, tudo por empenho de dona Margarida, que foi casada com Manuel Araújo de Carvalho, filho natural do coronel Manuel de Araújo de Carvalho, e que pretendia cinquenta ou sessenta mil cruzados dos bens da família Godim. ${ }^{32}$

Em posse de sua licença de Hábito Retento, Loreto Couto tocou sua vida: gerindo o patrimônio de suas irmãs, cuidando da educação de seus sobrinhos e da saúde de seu pai 
ancião, tratando seus achaques, viajando constantemente entre Pernambuco e Paraíba etc. Segundo ele, data desse período, fins da década de trinta do XVIII, a iniciação da redação de seu livro, concluído em $1757 .^{33}$

\section{Frade ou Monge?}

Ao se aproximar o ano de 1740, Loreto Couto decide romper definitivamente com os laços que lhe conectavam a Ordem dos Frades Menores alegando ser impossível a observância na ordem franciscana, por ser extremamente rigorosa. Utilizou então de um recurso ao Breve emitido pelo Papa Clemente XII, em 22 de janeiro de $1740,{ }^{34}$ para impetrar licença de trânsito para uma "religiam mais larga", menos rigorosa, afirmando serem "continuas as doenças sofridas ao longo de muitos anos e causadas pela observação à rigorosa regra quanto também para poder mais facilmente dar assistência a seu pai doente que é mais que octogenário e de várias de suas irmãs que eram viúvas e sobrinhos menores". 35

Em seu pedido de trânsito, Domingos do Loreto Couto não cogita largar a condição de eclesiástico regular, pelo contrário, sugere que a forma melhor para adequar sua realidade de tutor da família à carreira eclesiástica seria transitar para "religião mais larga", já que suas doenças teriam sido causadas "pela observação à rigorosa regra". ${ }^{36}$

Domingos do Loreto Couto, à semelhança de outros religiosos, realizou seu trânsito para a ordem de São Bento da França no mosteiro de Santa Maria do Crudácio, na Diocese de Viviers. O trânsito para as ordens francesas não implicava no deslocamento do professo, que permanecia na América Portuguesa, irmanado à nova forma de vida monacal e residindo em Pernambuco. Sabedor dessa prática, muito provavelmente a utilizou como estratégia, na medida em que lhe permitia viver junto a seus familiares, ter tempo para a dissertação do seu livro e, acima de tudo, lhe possibilitava continuar usufruindo da condição de eclesiástico, com os privilégios de foro correspondentes. ${ }^{37}$

O processo de trânsito de Domingos do Loreto Couto teve início em 1740, logo após a promulgação do Breve do Papa Clemente XII, destinado aos irmãos de São João Batista e de São José, da Ordem dos Frades Menores de São Francisco da Observância, da província da Espanha, que se estendia a Província de Santo Antônio do Brasil. De acordo com o Breve, ficava-se estabelecido que o trânsito seria permitido desde que as causas expostas fossem devidamente avaliadas interna e externamente, dependendo do consenso do capítulo provincial ou do pleno definitório. Conhecedor dessa prerrogativa, Domingos do Loreto Couto buscou outros caminhos para atingir seu objetivo. Como provavelmente já havia 
cultivado diversos inimigos entre os frades menores, dada a sua condição de "apóstata", acessou outros meios institucionais, talvez amparado na interpretação de que o fluxo de movimentação do organograma jurídico da Igreja Católica não necessariamente deveria atuar apenas da primeira instância para a última, mas, também, em sentido inverso.

Solicitou primeiramente liberação para o trânsito através da Cúria Patriarcal de Lisboa, já que essa instituição, na figura do cardeal patriarca, dispunha do mecanismo jurídico de concessão de indulgências, antes restrito ao cargo do Núncio Apostólico e da Santa Sé. ${ }^{38}$ Recebendo o beneplácito e a liberação do Patriarca de Lisboa, Domingos do Loreto Couto não precisaria temer a represália de seus confrades, já que teria a seu favor um instrumento jurídico que tinha a dimensão de romper o foro privado de sua ordem.

Entretanto, seu pedido foi indeferido pelo Patriarca de Lisboa, pois este entendeu que seu caso tratava-se de pura apostasia. Loreto Couto não titubeou em percorrer outro caminho para alcançar o seu propósito. Segundo uma carta de José dos Reis e Silva, Notário Apostólico e Escrivão, proprietário de um dos ofícios da relação e auditório da cúria patriarcal, Loreto Couto teria um agente em Lisboa que agravou sua causa para o Tribunal da Penitenciária, última instância de apelação em Roma no que tange às questões que perpassavam as causas de dispensa. ${ }^{39}$

A figura de um procurador (chamado de agente) em Lisboa e na Santa Sé nos leva a acreditar que durante seu período em Portugal tenha tecido importante rede de informações e de influência, que lhe permitia reduzir a distância geográfica entre América Portuguesa e o centro da cristandade, e se fazer representar face aos órgãos centrais do papado. Não é demais aludir que sua família tinha posses no Brasil, e que aos que tomavam o hábito religioso era comum que as famílias o apoiassem economicamente, com eles dividindo os bens. Assim, não se há de duvidar que Loreto Couto, por fazer parte de uma família de agricultores e senhores de terras, tenha conquistado e circulado por espaços de fortuna e poder em Portugal, que permitiu depois se valer destas amizades construídas no passado.

O Tribunal da Penitenciária foi favorável ao agravo de Loreto Couto. Considerando legítimo seu trânsito, lhe foi concedida licença para iniciar seu processo. Em 1742 seu nome era novamente citado no Patriarcado de Lisboa, dessa vez de forma exitosa. O Patriarcado recebia da Santa Sé Romana a delegação para iniciar o processo de trânsito de Domingos do Loreto Couto, que foi subdelegado pelo Cardeal Patriarca ao bispo de Pernambuco, Dom Frei Luiz de Santa Teresa (1739-1754), cabendo ao prelado o papel de levantar os autos de premissa que legitimariam ou não o trânsito de Loreto Couto. 
Um pouco antes da liberação de suas premissas, Loreto Couto já havia entrado em contato com a Ordem Beneditina, preconcebendo talvez a certeza da aprovação de seu processo. Segundo carta de Frei Manoel de São José, abade geral dos beneditinos do Brasil, em dezembro do ano de 1742, ou seja, antes inclusive da subdelegação das premissas de Dom Frei Luiz, Domingos do Loreto Couto o teria apresentado um decreto de sua santidade para usar de um indulto a seu favor, bem como uma carta patente do reverendíssimo João Ambruiz, prior geral de Santa Maria do Crudácio de São Bento da França. Nessa carta patente, afirmava-se que o trânsito para a ordem beneditina seria realizado pelo abade do Brasil, que deveria provê-lo com o hábito negro e lhe consignar mosteiro onde realizasse seu noviciado.

Não sabemos como Loreto Couto conseguiu a citada carta patente do geral dos beneditinos da França, haja vista que já a possuía, antes mesmo de aprovada suas premissas. Seguindo o perfil dos demais transitados, não fica claro em seu processo se a obteve em Portugal ou já na América Portuguesa, se foi adquirida por concessão direta do prior dos beneditinos ou por outro meio.

Segundo Frei Manoel de São José, antes de anuir ao pedido de Loreto Couto, aquele teria procurado o reverendo padre franciscano Manoel de Jesus Maria Colégio, comissário provincial do convento franciscano do Recife, através do emissário Manuel Francisco José do Egito, e, depois pessoalmente, para comunicá-lo sobre as pretensões de Loreto Couto. De acordo com o abade dos beneditinos, Fr. Manoel de Jesus Maria teria afirmado que Loreto Couto lhe tinha apresentado os Breves e liberações papais, e que não havia nenhum empecilho quanto a isso.

Como tudo parecia correr dentro da normalidade, o abade dos beneditinos afirma que teria vestido o hábito em Loreto Couto no dia três de fevereiro de 1743, ocasião em que estava presente toda a comunidade, inclusive representantes da ordem franciscana, onde se ficou determinado que Loreto Couto devesse cumprir seis meses de noviciado no Mosteiro de São Bento de Olinda. Concluso os seis meses de seu noviciado, o antigo "Frei" e agora Dom Domingos do Loreto Couto fez sua profissão no mosteiro beneditino de Olinda, em quatro de agosto de $1743 .^{40}$

Monge professo, Loreto Couto tocou sua vida como antes: cuidando dos avultosos bens de suas irmãs, da saúde de seu pai, da dissertação de sua obra, sem contudo recair sobre si o peso da apostasia. Isento da jurisdição dos franciscanos, respondia em primeira instância a um aparelho disciplinar que se encontrava do outro lado do Atlântico, o que o abonava 
inclusive da ação jurídica do mosteiro beneditino de Olinda, já que os ramos que compõem uma mesma ordem dispunham de autonomia jurídica.

\section{Embates Jurídicos entre a justiça eclesiástica e a justiça civil}

Em provisão de 21 de dezembro de 1742, enviada ao então governador de Pernambuco, Henrique Luís Pereira Freire de Andrade (1737-1746), ordenava-se que, se provadas às notícias que haviam chegado ao Conselho Ultramarino de que na dita capitania andava fora do seu convento com escândalo o padre Domingos do Loreto Couto, "o mandeis logo entregar ao seu prelado para que possa sair com efeito dessa mesma capitania". A provisão teria chegado às mãos do governador em fins de fevereiro ou início de março de 1743, quando o processo de justificação das premissas de trânsito já estava concluso a favor de Domingos do Loreto Couto.

Se na justiça eclesiástica seu processo aparentemente havia obtido êxito, na instância secular a sua condição não estava muito bem definida: se aos olhos do papa Loreto Couto estava apto ao trânsito, aos olhos do rei não passava de um ato "escandaloso". Na provisão enviada ao governador de Pernambuco, lê-se que havia chegado ao conselho ultramarino notícias sobre Loreto Couto, em que o delator confesso das acusações era o procurador geral da ordem franciscana, Frei Inácio das Neves, seu inimigo declarado.

Em resposta à provisão que lhe foi enviada, o governador Henrique Luís Freire de Andrade afirmou que lhe parecia estranho a vida do padre Domingos do Loreto Couto, por ter conhecimento de que há anos vivia fora do convento em casa de seus parentes segundo se fazia público. Sua desconfiança parece ter sido potencializada quando, ao receber o hábito dos beneditinos, Loreto Couto apareceu em público vestido de clérigo e com uma muleta "para melhor afetar a ocasião", o que se comprovou ser falso, segundo diz o governador, por ter aparecido no dia posterior ao olhar de todos "sem muleta nem lesão alguma". ${ }^{41}$

Henrique Luís Freire ainda afirma que era notório que o Breve utilizado por Loreto Couto era falso, e que este fingira ter remetido agravamento ao cardeal patriarca, o que fazia de suas premissas infundadas. Segundo o governador, era recorrente na "voz popular" que Loreto Couto não havia apresentado o Breve de trânsito na secretária de estado, muito menos aos seus prelados, e que, diferentemente do que era dito, não era tão bem quisto pelos seus parentes, que estimavam mais que ele se recolhesse à religião, do que tutelasse os bens da família. Havia ainda quem falasse que das "portas pra dentro" dos parentes andava mal encaminhado. $^{42}$ 
Percebe-se nitidamente duas linhas discursivas que começam a se descortinar em nossa narrativa: uma que apregoa a licitude e veracidade dos passos trilhados por Loreto Couto, que tem como nicho de influência uma parcela da elite local da Paraíba, o bispo de Pernambuco, a justiça eclesiástica e o Prior do Convento de São Bento; e outra encabeçada notadamente pelo Procurador Geral dos Franciscanos, bem como os órgãos concelhios da monarquia, já que o caso de Loreto Couto é produto de uma problemática mais ampla, os casos de trânsitos na América Portuguesa. Se ao Rei pouco importava um franciscano apóstata fora de seu convento, muito lhe interessava o disciplinamento de membros do clero vinculados à ordens sem cabeça no reino, ferindo assim o princípio do padroado régio.

O governador Henrique Luís Freire pôs em ação a determinação que lhe havia sido dada em três de fevereiro de 1743, aprisionando Loreto Couto e entregando-o no convento de São Francisco, onde deveria ser encarcerado pelos seus prelados.

Domingos do Loreto Couto afirma, em carta escrita ao rei, que o governador o prendeu de forma "publica e ignominiosamente no meio daquela praça por gente militar sendo ele eclesiástico e súbdito ao ordinário”. Segundo Frei Phelippe do Rozário, prior dos carmelitas descalços, teria sido Loreto Couto preso por um "capitão da infantaria e vários sargentos". A suposta desonra anunciada por Loreto Couto teria se dado por conta da perseguição efetuada pelo governador e pelo "pouco afeto que tem pelos presos e por todos os eclesiásticos".

Levado ao cárcere do convento franciscano, na vila do Recife, conduzido por agentes do governador, foi exposto ao olhar da população, aos murmúrios da boca miúda, em uma das áreas mais centrais da vila, no coração da praça mercantil. Percorrer a Rua de São Francisco, local onde se localizava o convento e a capela da Ordem Terceira dos franciscanos, onde sua família participou de forma efetiva da vivencia religiosa dessas instituições, deve ter sido um pesado golpe em Loreto Couto, que amargaria por dois anos o cárcere no convento.

Entretanto, o ímpeto de Fr. Luiz de Santa Tereza atuaria em favor de Loreto Couto, seja pela proximidade existente entre eles, já que Loreto Couto é constantemente apontado como protegido do bispo, seja pela defesa da jurisdição eclesiástica, uma das marcas do governo espiritual do carmelita. Já no dia 24 de dezembro do mesmo ano, seis dias após a prisão de Loreto Couto, Frei Luiz de Santa Tereza escrevia ao padre guardião do convento franciscano.

Em sua carta ao guardião, formaliza a queixa contra o procurador Frei Manuel Colégio, que segundo o bispo, enquanto aqui estava à frente do convento "não deixou de 
semear a discórdia, fazer enredos e prender com as suas mal fundadas desconfianças para o padre Frei Domingos do Loreto". Acusa o procurador de mortificar Loreto Couto, e de meter na cabeça do governador que fazia capítulos contra ele, malquistando-o com a religião. Para o prelado, teria sido o governador que enviou uma carta ao Conselho Ultramarino apontando as acusações contra Domingos do Loreto Couto.

A defesa de Frei de Luiz de Santa Tereza reside no fato de que no momento da prisão, Loreto Couto já havia transitado para a ordem beneditina, o que fazia infundada as acusações, haja vista que estas estariam vinculadas à sua situação de apostasia na ordem franciscana. Para embasar seu intento, Fr. Luiz acusa o procurador Frei Manuel Colégio de ter influenciado a decisão do governador. Por sua vez, o governador Henrique Luís Freire afirma que no cárcere Loreto Couto o quis imputar a culpa de sua prisão, respondendo ao prisioneiro que a prisão deveria ser colocada na conta do rei e da ordem franciscana. ${ }^{43}$

A dimensão dos embates gerados pela prisão de Loreto Couto tomaria proporções ainda maiores, em que o agente protagonista seria o bispo, Dom Fr. Luiz de Santa Tereza. Já na carta enviada ao guardião do convento franciscano do Recife, o bispo afirma que Loreto Couto havia apresentado seu Breve ao comissário do convento, e este havia enviado carta ao abade de São Bento, comunicando-lhe do trânsito. Segundo o abade Manoel de São José, o comissário franciscano, Manoel de Jesus Maria Colégio, havia lhe afirmado "que não tinha nenhuma dúvida nem coisa a dizer a respeito do seu trânsito", já que todos os prelados e mais religiosos da província conheciam os justificados motivos e urgentes causas de seu trânsito.

Para Dom Fr. Luiz, o culpado por ter difamado a imagem de Loreto Couto teria sido Fr. Manoel de Jesus Maria Colégio, que indisposto com a figura de Loreto Couto semeou as raízes de sua prisão. Para além da carga de pessoalidade impressa nesses discursos, entende-se nas entrelinhas da prisão de Loreto Couto questões locais de poder.

Segundo o Procurador Geral da Província de Santo Antônio do Brasil, Frei Inácio das Neves, Domingos do Loreto Couto foi logo retirado da casa de disciplina do convento de Santo Antônio "pelo empenho do excelentíssimo bispo", passando a lograr a mesma liberdade que os demais religiosos, sem, contudo, poder se retirar do convento. Em sua reclusão, que durou pouco mais de dois anos, amealhou quantidade considerável de certidões que objetivavam atestar suas qualidades e condição, bem como a clareza de seu processo de trânsito, tudo amparado na emissão de um Breve datado de quatro de maio de 1745, no qual o papa Bento XIV legitimava os processos de trânsito, contanto que fossem legais. ${ }^{44}$ 
Para Frei Inácio das Neves, o bispo, Fr. Luiz de Santa Tereza, teria sido o agente favorecedor da libertação de Loreto Couto, além de afirmar que parte dos que assinaram as certidões nem se quer conheciam Loreto Couto, e só o fizerem pelo empenho do bispo de Pernambuco. ${ }^{45}$

A relação de Fr. Luiz com a causa de Domingos do Loreto Couto não se restringiria a suposta "intimidade" que o bispo nutria com os depoentes que testemunharam a favor de Loreto Couto, chegaria à esfera do embate jurídico, que se iniciaria com a emissão de um novo Breve, datado de quatro de março de 1746. Segundo carta do governador que sucedeu Henrique Luiz Freire, D. Marcos de Noronha (1746-1749), $7^{\circ}$ Conde dos Arcos, teria Domingos de Loreto Couto conseguido junto a Sé Apostólica novo Breve que permitia ao ordinário do bispado dar "remédio a esta matéria, como fosse justiça". A matéria em questão tratava-se claramente da prisão de Loreto Couto, que, a partir de então, recorreu ao bispo Fr. Luiz de Santa Tereza, amparado nas letras papais.

A resposta de Fr. Luiz de Santa Tereza não tardaria, utilizando os instrumentos que lhe eram possíveis, declarou obreticia ${ }^{46}$ e subreticia $^{47}$ à provisão real de 21 de outubro de mil setecentos e quarenta e dois, que exigia do governador Henrique Luiz Freire a prisão de Loreto Couto, ameaçando sob pena de excomunhão aquele que se opusesse a dar liberdade a Domingos do Loreto Couto.

Declarar obreticia e subtrecia uma provisão real, significava literalmente revogar o mandado do monarca, considerando-a improcedente, tanto em termos de legalidade jurídica, quanto no que toca ao objetivo da penalização. ${ }^{48}$

\section{Dos Desagravos às Glórias}

O decorrer da década de cinquenta foi marcante na trajetória de Domingos do Loreto Couto: se por um lado amedrontou-se diante da possibilidade de ser retirado da América Portuguesa e remetido à França, por outro viveu talvez a fase mais exitosa de sua vida, desde que retornara de Lisboa. Longe da reclusão desde 1746, Loreto Couto tocou sua vida como monge beneditino, figurando como sujeito de prestígio entre os grandes da terra, ocupando cargos na burocracia eclesiástica, servindo como testemunha em processos de habilitação para o recebimento do Hábito de Cristo e sendo reconhecido como escritor prestimoso.

Segundo José Antônio Gonçalves de Mello, no início dos anos cinqüenta, Domingos do Loreto Couto tornou-se visitador do bispado de Pernambuco ao tempo em que o bispo continuava sendo Frei Luiz de Santa Teresa. Teria visitado a paróquia de Nossa Senhora da 
Boa Viagem em três de novembro de 1751, segundo se faz registrado no livro de receitas e despesas da referida capela. ${ }^{49}$

Não sabemos precisar até que data ocupou o cargo de visitador, mas acreditamos que o tenha ocupado até a saída de Fr. Luiz de Santa Tereza, em 1754, já que em 1757 se apresenta em seu livro como "visitador que foi do bispado de Pernambuco". ${ }^{50}$ Como a documentação referente à câmara eclesiástica e ao auditório eclesiástico da Capitania de Pernambuco se perdeu com o tempo, não conseguimos mensurar a atuação de Loreto Couto enquanto visitador, para além da visita que realizou a Paróquia de Nossa Senhora de Boa Viagem.

Em fins da década de cinquenta Loreto Couto concluiria um projeto que há mais de vinte e cinco anos se dedicava. Chegava ao fim à redação de sua obra, intitulada Desagravos do Brasil e Glória de Pernambuco: Discursos brasílicos, dogmáticos, bélicos, apologéticos, morais e históricos, datada de 26 de março de 1757. A conclusão do seu livro lhe proporcionaria a concessão do cargo de Acadêmico Supranumerário da Academia Brasílica dos Renascidos. ${ }^{51}$

A participação de Loreto Couto entre os acadêmicos é um demonstrativo de sua importância e figuração entre a elite pernambucana de então, sua indicação para o cargo não se resume apenas a destreza de sua pena, mas ao prestígio que cultivou nos anos que retornou a Pernambuco. De acordo com os Estatutos da Academia Brasílica dos Renascidos (1759), o título de acadêmico supranumerário apenas podia ser concedido a sujeitos com parcimônia e madura reflexão, devendo cada bispado da América Portuguesa ter no mínimo dois representantes nessa condição. No que toca ao bispado de Pernambuco, além de Domingos do Loreto Couto, foram investidos do título de supranumerário Antônio Vitoriano José Borges da Fonseca, que por sinal era seu amigo particular, e Fr. Antônio de Santa Maria Jaboatão, dois dos mais importantes escritores setecentistas da história pernambucana. ${ }^{52}$

Na carta enviada a Antônio Gomes Ferrão Castelo Branco, secretário da Academia Brasílica, Loreto Couto se diz lisonjeado em ter seu nome inscrito no catálogo de tão sábios, egrégios e ilustres acadêmicos. Afirma que há 25 anos lhe tem perseguido os achaques, e que nas tréguas que lhe permitiam, as empregou em escrever a história de Pernambuco, dado que lhe causava imensa dor ver "as memórias de tantos ilustres varões, naturais de minha pátria, que em todas as quatro partes do mundo fizeram célebre o seu nome, pelas virtudes, letras e armas", serem sepultadas na triste urna do esquecimento. ${ }^{53}$

Faz menção ao período em que foi visitador geral do bispado de Pernambuco ao afirmar que escreveu sua obra: 
Estribado em verídicas informações de pessoas de 80, 90, 100 anos nas observações e exames que fiz, quando fui visitador geral desse bispado, nos casos e sucessos que presenciei, de que há milhares de testemunhas em alguns memoriais que por ventura me vieram as mãos e em notícias que extrair das secretárias e cartórios. ${ }^{54}$

Percebe-se que a atuação de Loreto Couto enquanto visitador lhe foi importante ao seu propósito de escritor, na medida em que lhe permitiu ter acesso livre aos arquivos paroquiais, o que parece ter sido uma perspectiva metodológica utilizada por ele, já que diz que pouco "se valeu de livros que tratam do nosso Brasil, porque neles há muitas fábulas e bastantes calúnias". ${ }^{55}$ Um exemplo de que seu cargo tenha servido como facilitador ao seu propósito literário, (foram) as estatísticas populacionais traçadas por Loreto Couto para a Capitania de Pernambuco e suas anexas, muito provavelmente as realizou tendo em vista as listas de desobriga do bispado de Olinda, como nos lembra José António Gonsalves de Mello. ${ }^{56}$

Sua obra foi dedicada ao Rei D. José I “por mão do excelentíssimo senhor Sebastião José de Carvalho e Mello", que segundo Loreto Couto é oriundo de Pernambuco, dada a sua genealogia, que compreende nomes como Jerônimo de Albuquerque e Francisco de Mendonça Furtado. Claramente pretendia sensibilizar o conde de Oeiras no apadrinhamento de sua obra, o que parece não ter surtido efeito, como já dito anteriormente. Afirma que seu livro foi levado a Portugal pelo governador Luiz José Correia de Sá (1749-1756), sucessor de D. Marcos Noronha.

No diário particular de Luiz José Correia de Sá, impresso e publicado pelo IAHGP, não constatamos nenhuma menção ao transporte do livro, muito menos nenhuma audiência entre Loreto Couto e o governador, como comumente foi registrado por Correia de Sá em relação a outros sujeitos, o que não anula a afirmativa de Loreto Couto, entretanto, entendemos que exista uma incompatibilidade cronológica, já que o governo de Luiz Correia de Sá estende-se até fevereiro de 1756, enquanto Loreto Couto afirma ter concluído a obra em 26 de março de $1757 .^{57}$ Não se descarta a possibilidade da obra ter sido enviada a Portugal e entregue ao ex-governador, para que esse a remetesse a Sebastião José de Carvalho e Mello, o que demonstra a intimidade que nosso transitado nutria com as elites administrativas na Capitania de Pernambuco.

Em fins da década de cinquenta encontramos Domingos do Loreto Couto novamente figurando entre a elite local, participando das solenidades realizadas em Pernambuco em louvor a D. José I, depois do atentado em que o Rei foi alvo em 1759. É citado como "o muito reverendíssimo Padre Dom Domingos do Loreto Couto, visitador geral que foi deste 
bispado", pregando no dia 29 de junho de 1759, na Igreja do Corpo Santo na Freguesia de São Pedro Gonçalves, onde realizou seu discurso "com tanta propriedade ao intento, que tendo apenas três dias pareceu de muitos meses pela elegância e sutileza com que discorreu, pela erudição de notícias, e nervosidade de razões com que persuadiu". ${ }^{58}$ A citada solenidade, que durou alguns dias, teve a participação de importantes agentes de poder, dentre eles: o bispo de Olinda, o governador da capitania, os prelados de todos os conventos com seus religiosos (incluem-se os franciscanos), toda nobreza e pessoas principais etc.

Aceito como "Dom" pela elite local, ocupando cargos de prestígio no ordinário do bispado, reconhecido como escritor, Loreto Couto viveu as glórias do que talvez tenha planejado desde que o seu trânsito foi solicitado, usufruindo de uma condição jurídica impar dentro do quadro de poderes eclesiásticos na América Portuguesa, já que, de acordo com Fr. Luiz de Santa Tereza, Loreto Couto ficaria sob a sujeição do ordinário do bispado apenas até o momento em que concretizasse seu trânsito, com esse efetuado, seria regido pela regra de sua ordem, tal qual qualquer outro clérigo regular, já que era permitido a esses, mesmo que não tivesse superior no reino, a utilização do foro privilegiado. ${ }^{59}$

Como Loreto Couto permaneceu em Pernambuco, era literalmente regido em primeira instância por um abade que estava do outro lado do Atlântico, e que provavelmente nem sequer o conhecia, o que pareceu não ter sido problema algum para o decurso de sua vida, pelo contrário, basicamente o que teria almejado para seu futuro fora realizado, sua condição se plasmou sem problemas à plasticidade normativa do Império Português, não escondeu em momento algum sua realidade de transitado, como se pode ver na folha de rosto de sua obra, quando se intitula "Presbítero Professo da Ordem do Principe dos Patriarchas S. Bento, na congregação de Santa Maria de Crudacio da Diocese vivarience, do reino da França", o que nos leva a olhar o caso de Loreto Couto e dos demais transitados não pela lente da exceção, mas sim pelo visor de uma prática que se mostrou recorrente e possível dentro da lógica polissinodal, própria a monarquias como a portuguesa da época moderna.

Não sabemos a data de morte de Domingos do Loreto Couto, nem o rumo que sua vida tomou no decorrer na década de 60. A última referência documental encontrada data de cinco de novembro de 1762, quando Domingos do Loreto Couto aparece como testemunha do processo de José Carlos Paes Barreto, que solicitava ao Rei o posto de tenente no regimento de infantaria do Recife. ${ }^{60}$ 


\section{Notas}

${ }^{1}$ Religioso moço que serve no coro. Ver. BLUTEAU, Raphael. Vocabulario portuguez \& latino: aulico, anatomico, architectonico. Vol. 2. Coimbra: Collegio das Artes da Companhia de Jesus, 1712 - 1728.

${ }^{2}$ AHU - Avulsos de Pernambuco - cx.67, doc. 5691 - 06/04/1748.

${ }^{3}$ Supomos essa data a partir de declaração realizada pelo próprio Loreto Couto no ano de 1762, quando ao testemunhar a favor da petição impetrada por José Carlos Paes Barreto, que pretendia a patente de tenente no regimento de infantaria do Recife, afirmou ter 66 anos. Ver. ANTT - Ministério do Reino, Mç. 316, Cx. 423. Segundo José Antônio Gonsalves de Mello, existiria outro registro onde Loreto Couto afirmava ter setenta anos, entretanto a localização da fonte dada pelo autor não é compatível com a encontrada no Arquivo Nacional da Torre do Tombo. Recife: FUNDARPE, 1986. p.196.

${ }^{4}$ COUTO, D. Domingos do Loreto. Desagravos do Brasil e Glórias de Pernambuco. Recife: Fundação de Cultura da Cidade do Recife, 1981. p.398.

${ }^{5}$ Ver. OFM. Livro Primeiro de Termos de entradas de p.1 a p.146. Professoes 147 a 322 dos anos de 1695 a 1722. Fl. 58.

${ }^{6}$ PIO, Fernando. A Ordem Terceira de São Francisco do Recife e suas Igrejas. Recife, 1975.

${ }^{7}$ COUTO, Domingos do Loreto Couto. Desagravos e Glórias de Pernambuco. op. cit.,p. 160.

${ }^{8}$ Ver. OFM. Livro Primeiro de Termos de entradas de p.1 a p.146. Professoes 147 a 322 dos anos de 1695 a 1722. Fl. 234

${ }^{9}$ Entende-se por Couto povoação que por estar distante das vilas e cidades, tem suas justiças e tem suas terras e lugares anexos, cujos negócios pertencem aos juízes, que nela assistem, e é lugar privilegiado em que se acolhem devedores e malfeitores. BLUTEAU, Raphael. Vocabulario portuguez \& latino: aulico, anatomico, architectonico. Vol. 2. Coimbra: Collegio das Artes da Companhia de Jesus, 1712 - 1728. p. 596. No caso em questão o Couto vinculava-se a paróquia de São Pedro dos Capareiros, que havia sido um mosteiro beneditino, fixado no quinhão de terra doado a Sé de Braga por Payo Paes em 1126. COSTA, Antônio Carvalho da. Corografia Portuguesa e descrição Topográfica do Famoso Reino de Portugal. Lisboa: Oficina de Valentim da Costa Deslandes, 1706. p. 186.

${ }^{0}$ COUTO, D. Domingos do Loreto. Desagravos do Brasil e Glórias de Pernambuco. Recife: Fundação de Cultura da Cidade do Recife, 1981. p.398.

${ }^{11}$ ANTT. HSO Domingos Rodrigues Bandeira. M. 14, d. 316. In. SOUZA, George Felix Cabral. Tratos e Mofatras: o grupo mercantil do Recife colonial (1654 - 1759). Recife: editora da Universidade Federal de Pernambuco, 2012. p. 511.

${ }^{12}$ Ibid. p. 160.

${ }^{13}$ Segundo George Cabral, a atuação de um padrinho como elemento de conexão e acolhida no novo mundo era prática comum entre os agentes mercantis do Recife nascidos em Portugal. Exemplo clássico na literatura Pernambucana é a rede comercial criada pela família Favais, originária dos trás-montes, no romance Emparedada da Rua Nova. Ver. VILELA, Carneiro. A Emparedada da Rua Nova. Recife: CEPE, 2013.

${ }^{14}$ REGO, João de Figueiroa; OLIVAL, Fernanda. Cor da pele, distinções e cargos: Portugal e espaços atlânticos portugueses (séculos XVI a XVIII). Revista Tempo, nº 30, julho de 2010.

${ }^{15}$ BOXER, Charles. O Império Marítimo Português. São Paulo: Companhia das Letras, 2002. p. 286.

${ }^{16}$ Idem. p. 300 .

${ }^{17}$ MELLO, Evaldo Cabral de. A Fronda dos Mazombos: nobres contra mascates Pernambuco, 1666 - 1715. São Paulo: Ed. 34, 2003. p. 156.

18 JABOATÃO, Frei Antônio de Santa Maria. Nova Orbe Seráfico Brasílico ou Chronica dos Frades Menores da Província do Brazil. Vol. II. Rio de Janeiro: Typografia Brasiliense de Maximiano Gomes Ribeiro, 1858. p. 371.

COUTO, D. Domingos do Loreto. Desagravos do Brasil e Glórias de Pernambuco. Recife: Fundação de Cultura da Cidade do Recife, 1981. p.269. Seu avô, Bartolomeu Soares Canha, teria sido um dos principais restauradores de Pernambuco na invasão dos holandeses. Ver. ANTT - Mesa das Consciências e Ordens, Padroado do Brasil, Bispado de Pernambuco. Mç. 12.

${ }^{20}$ SAMPAIO, Antônio Carlos Jucá de. Os homens de negócios e a coroa na construção das hierarquias sociais: o Rio de Janeiro na primeira metade do século XVIII. In: Na trama das redes: política e negócio no Império Português, séculos XVI -XVIII. Rio de Janeiro: Civilização Brasileira, 2010. p. 472.

${ }^{21}$ Ver. MONTEIRO, Nuno Gonçalves. A Crise de Um Modelo. In. O Crepúsculo dos Grandes: a casa e o patrimônio da Aristocracia em Portugal. Lisboa: Imprensa Nacional - Casa da Moeda, 2003. pp. 169-197.

${ }^{22}$ Estatuto da Província de Santo Antonio do Brasil. Lisboa: Oficina de Manoel e Joseph Lopes Ferreyra, 1709.p.13.

${ }^{23}$ AHU - Avulsos de Pernambuco - cx.67, doc. 5691 - 06/04/1748.

${ }^{24}$ AHU - Avulsos de Pernambuco - cx.67, doc. 5691 - 06/04/1748. A partir de então nossa narrativa tomará prioritariamente como base o processo de Domingos do Loreto Couto, depositado entre os avulsos do Conselho 
Ultramarino, inventariado pelo projeto resgate. O referido processo é composto por mais de 80 fólios, com quantidade considerável de anexos.

${ }^{25}$ Para uma descrição mais pormenorizada da cidade de Salvador no período, ver. WOOD, Russel. Fidalgos e Filantropos: A Santa Casa de Misericórdia da Bahia, 1550 - 1775. Brasília: Editora da Universidade de Brasilia, 1981. p. 40.

${ }^{26}$ Em relação às ordens regulares designava aquele que sem licença nem ordem dos prelados vive fora de seu convento. Estatuto da Província de Santo Antonio do Brasil. Op. cit.

${ }^{27}$ AHU - Avulsos de Pernambuco - cx.67, doc. 5691 - 06/04/1748. Tal modelo de disciplina era previsto no estatuto da província de Santo Antônio. Ver. Estatuto da Província de Santo Antonio do Brasil. Lisboa: Oficina de Manoel e Joseph Lopes Ferreyra, 1709.

${ }^{28}$ AHU - Avulsos de Pernambuco - cx.67, doc. 5691 - 06/04/1748.

${ }^{29}$ A carta escrita pelo citado abade data de 1744, nela lê-se: "E também atesto que o dito padre Domingos antes de fazer o seu transito esteve perto de sete anos assistindo com licença dos seus prelados em casa de seus pais e irmãs viúvas". Idem. Como veremos adiante, o trânsito teria ocorrido no ano de 1743.

${ }^{30}$ MELLO, José Antônio Gonsalves de. "Loreto Couto e os Desagravos do Brasil e Glórias de Pernambuco". In. Estudos pernambucanos. Recife: FUNDARPE, 1986.p. 201.

${ }^{31}$ OFM. Livro Primeiro de Termos de entradas de p.1 a p.146. Professoes 147 a 322 dos anos de 1695 a 1722. Fl. 155.

${ }^{32}$ AHU - Avulsos de Pernambuco - cx.67, doc. 5691 - 06/04/1748. Segundo Loreto Couto, o coronel Manoel Araújo de Carvalho teria sido o dominador dos índios dos distritos de Cariri, Piranhas e Piancó, onde era proprietário de fazendas de gado. COUTO, Domingos do Loreto. Desagravos do Brasil e Glórias de Pernambuco. Recife: fundação de cultura da cidade do Recife, 1981.

${ }_{33}$ BNL - Papéis da Academia Brasílica dos Renascidos. Cod. 630. Fol. 97.

${ }^{34}$ Para uma visão mais ampla da questão, ver. MELO, Bruno Kawai Souto Maior de. Desagravos e Glórias: trânsito, transitados e relações jurídico-religiosas no Império Português (1696-1762). Dissertação de mestrado apresentada ao programa de pós-graduação em História da UFPE, 2015. pp. 89-99.

${ }^{35}$ AHU - Avulsos de Pernambuco - cx.67, doc. 5691 - 06/04/1748.

${ }^{36}$ Por trânsito deve-se entender um arranjo de mobilidade horizontal, onde o religioso utilizando um Breve emitido pela cúria papal transitava entre províncias de uma mesma congregação ou ainda para outra ordem religiosa. Ver. MELO, Bruno Kawai Souto Maior de. "Nem Clérigo, Nem Frade, Nem Sogeição a Ninguém": trânsito e transitados em Pernambuco na Primeira Metade dos Setecentos. In. Dimensões do Catolicismo no Império Português (séculos XVI-XIX). Rio de Janeiro: Garamond, 2014. p. 109.

${ }^{37}$ Idem.

${ }^{38}$ ALMEIDA, Fortunado de. História da Igreja em Portugal. Vol. IV. Livraria Civilização - Editora: Porto Lisboa, 1968. p. 208.

${ }^{39}$ Ver. BRAMBILLA, Elena. "Penitenzieria Apostolica". In. Dizionario storico dell'Inquisizione. Paolo Prodi (Org.). Vol. III. Pisa: Edizione dela Normale. p. 1183.

${ }^{40}$ Idem.

${ }^{41}$ Idem.

42 AHU - Avulsos de Pernambuco - cx.60, doc. 5104 - 02/02/1744. A documentação enviada pelos governadores de Pernambuco as Secretaria de Estado inicia-se a partir de 1784, como se pode ver nos volumes depositados no Arquivo Público Estadual Jordão Emerenciano (APEJE). Quanto à secretária de governo de Pernambuco, já começa a funcionar em fins do século XVII, sendo seu regimento datado de 1688, como afirma Maria de Fátima Gouvêia. Ver. GOUVÊA, Maria de Fátima. Redes Governativas Portuguesas e centralidades régias no mundo português (1680-1730). In: Na trama das redes: política e negócio no Império Português, séculos XVI -XVIII. Rio de Janeiro: Civilização Brasileira, 2010. p. 177.

${ }^{43}$ AHU - Avulsos de Pernambuco - cx.60, doc. 5104 - 02/02/1744.

${ }^{44}$ ANTT - Ordem dos Frades Menores, Província de Santo António, mç. 4.

${ }^{45}$ Idem.

${ }^{46}$ Segundo Raphael Bluteau, entende-se por obretecia o ato de calar alguma circunstância de fato, ou direito, para se obter algum despacho , que senão obtivera, ou não devera dar declarada a tal circunstância encoberta dolosamente. Op., cit.

${ }^{47}$ Por subreptícia entende-se algo que se faz ou se toma ocultamente e as escondidas. Ver. Real Academia Espanõla. Diccionario de la Lengua Castellana. Madrid, 1739.

${ }^{48}$ AHU - Avulsos de Pernambuco - cx.67, doc. 5691 - 06/04/1748.

${ }^{49}$ MELLO, José Antonio Gonsalves de. op. cit., 1951. Não conseguimos encontrar a documentação referente à paróquia de Nossa Senhora da Boa Viagem, o que nos impossibilita de compreender como se deu a atuação de Loreto Couto no exercício do seu ofício. 


\footnotetext{
${ }^{50}$ COUTO, Dom Domingos do Loreto. Op. cit.

${ }^{51} \mathrm{O}$ cargo de acadêmico supranumerário seria uma espécie de correspondente à distância, já que a academia sediava-se na Bahia. De acordo com o estatuto, cada bispado poderia ter em media dois representantes na condição de supranumerário. Ver. Estatuto da Academia Brasílica dos Renascidos. Revista do Instituto Histórico Geográfico Brasileiro. Tomo XLV. Rio de Janeiro, 1882.

${ }^{52}$ BNL - Papéis da Academia Brasílica dos Renascidos. Cod. 630.

${ }^{53}$ BNL - Papéis da Academia Brasílica dos Renascidos. Cod. 630. Fl. 97-105.

${ }^{54}$ Idem. Fl. 97.

${ }^{55}$ Para uma análise da obra de Loreto Couto, suas particularidades, inovações, o empréstimo de palavras que faz de outros autores, a exemplo de Fr. Vicente do Salvador, ver. MELLO, José Antônio Gonsalves de. Loreto Couto e os Desagravos do Brasil e Glórias de Pernambuco. In. Estudos Pernambucanos. Recife: FUNDARPE, 1986. pp. 210-224; KANTOR, Iris. Esquecidos e Renascidos. Historiografia Acadêmica Luso-Americana (1724-1759). São Paulo/Salvador: Hucitec, 2004. pp. 226-232; SILVA, Bruno. "Fabricando" Identidades: Domingos Loreto Couto, Vida e obra de um Cronista Luso-Brasileiro na Pernambuco de Meados do Século XVIII. Revista Cantareira jul.-dez./2011. Disponível em: http://revistacantareira.files.wordpress.com/2012/01/e2809cfabricandoe2809d-identidades-domingos-loretocouto-vida-e-obra-de-um-cronista1.pdf.

${ }^{56}$ MELLO, José Antônio Gonsalves de. Loreto Couto e os Desagravos do Brasil e Glórias de Pernambuco. op. cit. p. 217.

${ }^{57}$ O Diário do Governador Correia de Sá. Revista do IAHGP. Vol. LVI. Recife, 1983.

${ }^{58}$ AHU - Avulsos de Pernambuco - cx.93, doc. 7398- 20/04/1760. Agradecemos a pesquisadora Noely Gomes da Silva pela gentileza em nos apontar e ceder o referido documento.

59 HESPANHA, António Manuel. Direito Luso Brasileiro no Antigo Regime. Florianópolis: Fundação BOITEUX, 2005. p. 329.

${ }^{60}$ ANTT - Ministério do Reino, Mç. 316, Cx. 423.
}

\section{Referências Bibliográficas}

ALMEIDA, Fortunado de. História da Igreja em Portugal. Vol. IV . Livraria Civilização Editora: Porto - Lisboa, 1968.

BOXER, Charles. O Império Marítimo Português. São Paulo: Companhia das Letras, 2002. BLUTEAU, Raphael. Vocabulario portuguez \& latino: aulico, anatomico, architectonico. Vol. 2. Coimbra: Collegio das Artes da Companhia de Jesus, 1712 - 1728.

COSTA, Antônio Carvalho da. Corografia Portuguesa e descrição Topográfica do Famoso Reino de Portugal. Lisboa: Oficina de Valentim da Costa Deslandes, 1706.

COUTO, D. Domingos do Loreto. Desagravos do Brasil e Glórias de Pernambuco. Recife: Fundação de Cultura da Cidade do Recife, 1981.

HESPANHA, António Manuel. Direito Luso Brasileiro no Antigo Regime. Florianópolis: Fundação BOITEUX, 2005.

JABOATÃO, Frei Antônio de Santa Maria. Nova Orbe Seráfico Brasílico ou Chronica dos Frades Menores da Província do Brazil. Vol. II. Rio de Janeiro: Typografia Brasiliense de Maximiano Gomes Ribeiro, 1858.

PIO, Fernando. A Ordem Terceira de São Francisco do Recife e suas Igrejas. Recife, 1975.

MELO, Bruno Kawai Souto Maior de. Desagravos e Glórias: trânsito, transitados e relações jurídico-religiosas no Império Português (1696-1762). Dissertação de mestrado apresentada ao programa de pós-graduação em História da UFPE, 2015.

"Nem Clérigo, Nem Frade, Nem Sogeição a Ninguém”: trânsito e transitados em Pernambuco na Primeira Metade dos Setecentos. In. Dimensões do Catolicismo no Império Português (séculos XVI-XIX). Rio de Janeiro: Garamond, 2014. 
MELLO, Evaldo Cabral de. A Fronda dos Mazombos: nobres contra mascates

Pernambuco, 1666 - 1715. São Paulo: Ed. 34, 2003.

MELLO, José Antônio Gonsalves de. Loreto Couto e os Desagravos do Brasil e Glórias de Pernambuco. In.Estudos Pernambucanos. Recife: FUNDARPE, 1986.

MONTEIRO, Nuno Gonçalves. O Crepúsculo dos Grandes: a casa e o patrimônio da Aristocracia em Portugal. Lisboa: Imprensa Nacional - Casa da Moeda, 2003.

REGO, João de Figueiroa; OLIVAL, Fernanda. Cor da pele, distinções e cargos: Portugal e espaços atlânticos portugueses (séculos XVI a XVIII). Revista Tempo, $\mathrm{n}^{\circ}$ 30, julho de 2010.

SAMPAIO, Antônio Carlos Jucá de. Os homens de negócios e a coroa na construção das hierarquias sociais: o Rio de Janeiro na primeira metade do século XVIII. In: Na trama das redes: política e negócio no Império Português, séculos XVI -XVIII. Rio de Janeiro: Civilização Brasileira, 2010.

SOUZA, George Felix Cabral. Tratos e Mofatras: o grupo mercantil do Recife colonial (1654 - 1759). Recife: editora da Universidade Federal de Pernambuco, 2012. WOOD, Russel. Fidalgos e Filantropos: A Santa Casa de Misericórdia da Bahia, 1550 1775. Brasília: Editora da Universidade de Brasilia, 1981. 